\title{
Programmed Death Ligand 1 (PD-L1) Expression in Malignant Mesenchymal Tumors
}

\author{
Kemal KÖSEMEHMETOĞLU', Ece ÖZOĞUL', Berrin BABAOĞLU', Gaye GÜLER TEZEL1,2, Gökhan GEDIKOĞLU'
}

'Department of Pathology and 'Molecular Pathology, Research and Application Center, Hacettepe University, Faculty of Medicine, ANKARA, TURKEY

\begin{abstract}
Objective: Programmed death ligand 1 (PD-L1) found on tumor cells has recently been reported to have a key role in the development and dissemination of many tumors, such as lung and breast carcinomas. In this study, we retrospectively analyzed PD-L1 expression among different types of sarcomas.

Material and Method: Tissue microarrays of 3-4 mm diameter were composed from paraffin blocks of 222 various sarcomas. Slides prepared from microarrays were stained for PD-L1 antibody (Cell Signaling, E1L3N ${ }^{\circledR}$ ) using Leica Bond Autostainer. Any membranous staining over $5 \%$ of the cells was regarded as positive. Quantitative real-time PCR with TaqMan gene expression assays for PDL1 was performed using whole sections from FFPE tissue of PD-L1 positive cases, by normalizing absolute values to $\beta$-actin. Relative expression level of mRNA of PDL1 was calculated and scored using $\log _{10} 2^{\text {(threshold cycle of b-actin - threshold cycle of PDL1). }}$

Results: Immunohistochemically, PD-L1 expression was present in 34 of 222 (15\%) sarcomas. 5/13 (39\%) undifferentiated pleomorphic sarcomas, 6/18 (33\%) malignant peripheral nerve sheath tumors, 5/16 (31\%) dedifferentiated liposarcomas, 4/19 (21\%) rhabdomyosarcomas, 2/16 (13\%) epithelioid sarcomas, $2 / 15$ (13\%) leiomyosarcomas, 3/26 (12\%) synovial sarcomas, 1/18 (6\%) myxoid liposarcoma, 1/2 (50\%) extraskeletal myxoid chondrosarcoma, 1/3 (33\%) alveolar soft part sarcoma, 1/3 (33\%) parachordoma/myoepithelioma, 1/5 (20\%) pleomorphic liposarcoma, 1/7 (14\%) angiosarcoma, 1/8 (13\%) Ewing sarcoma showed PD-L1 expression. Cases of solitary fibrous tumor/hemangiopericytoma (18), desmoplastic round cell tumor (14), Ewing-like sarcoma (6), epithelioid hemangioendothelioma (5), clear cell sarcoma (4), myxofibrosarcoma (4), low grade fibromyxoid sarcoma (2) were all negative. Tumor-infiltrating hematopoietic cells were positive for PD-L1 in 32 cases (15\%) with only 2 cases overlapping with PD-L1 staining in tumoral cells. Sixteen of 34 (47\%) immunohistochemically PD-L1 positive cases showed significant but low-level PD-L1 mRNA overexpression.
\end{abstract}

Conclusion: We have shown PD-L1 expression in a subset of sarcomas, both at the protein and mRNA level. High-grade pleomorphic sarcomas tend to show more frequent PD-L1 expression. Clinical trials are necessary to further assess the effect of anti PD-L1 drugs on sarcomas showing PD-L1 expression.

Key Words: Sarcoma, Immunotherapy, Immunohistochemistry, Quantitative PCR

\section{INTRODUCTION}

PD-L1, CD274 or B7 homolog 1 (B7-H1) is a $40 \mathrm{kD}$ type 1 transmembrane protein found on activated $\mathrm{T}$ cells, $\mathrm{B}$ cells and myeloid lineage members plays an important role in regulation of cellular immune response (1). Activation of PD-1/PD-L1 complex leads to inhibition of antigen specific $\mathrm{T}$ cell proliferation and induces apoptosis of these antigen specific T cells. It is hypothesized that PD-L1 expression in neoplastic cells enhances its disguise ability to escape from the immune system. Many studies have shown increased expression of PD-L1 ligand in various cancers arising from the lung, skin, ovary, cervix, esophagus, breast, bladder, brain, bone, kidney, and liver (2-7).

Management of primary sarcoma is basically surgery, while chemotherapy or radiotherapy has only marginal effect on metastatic sarcomas. Immunotherapy with anti PD-L1

(Turk Patoloji Derg 2017, 33:192-197)

Received : 05.01.2017 Accepted : 07.03.2017 monoclonal antibodies is a promising treatment option in the management of metastatic sarcoma. Therefore, in this study we investigated the presence of PD-L1 expression among sarcomas at both the protein and RNA expression level.

\section{MATERIAL and METHODS}

Slides of 222 cases of various sarcomas were retrieved from the archive and the diagnoses were reviewed (KK). Twentysix synovial sarcomas, 19 rhabdomyosarcomas, 18 myxoid liposarcomas, 18 malignant peripheral nerve sheath tumors, 18 solitary fibrous tumor/hemangiopericytomas, 16 dedifferentiated liposarcomas, 16 epithelioid sarcomas, 15 leiomyosarcomas, 14 desmoplastic round cell tumors, 13 undifferentiated pleomorphic sarcomas, 8 Ewing sarcomas, 6 Ewing-like sarcomas, 7 angiosarcomas, 5 epithelioid hemangioendotheliomas, 5 pleomorphic liposarcomas, 4

Correspondence: Kemal KÖSEMEHMETOĞLU

Hacettepe University Faculty of Medicine,

Department of Pathology, ANKARA, TURKEY

E-mail: dokemal@hotmail.com Phone: +90 3123051555 
clear cell sarcomas, 4 myxofibrosarcomas, 3 alveolar soft part sarcomas, 3 parachordoma/myoepiheliomas, 2 extraskeletal myxoid chondrosarcomas, 2 low grade fibromyxoid sarcomas were included in the study. Bone tumors, such as osteosarcomas and chondrosarcomas, and mesenchymal tumors with indolent clinical behavior, such as atypical lipomatous tumor/well differentiated liposarcoma were excluded.

Representative areas were selected and 3-4 mm diameter tissue microarrays were composed from paraffin blocks. Microarray slides were stained for PD-L1 antibody (Cell Signaling, E1L3N $\left.{ }^{\star}, 1 / 400\right)$ using Leica Bond Autostainer, according to the manufacturer's instructions. Antigen retrieval was performed with EDTA pretreatment for 20 minutes. Any membranous staining over $5 \%$ of the cells was regarded as positive. PD-L1 expression in tumor infiltrating inflammatory cells was also noted.

Quantitative real-time PCR with Fast-Plus EvaGreen Master Mix (Cat No:31020, Biotium) and gene expression assays for CD274 was performed using whole sections from FFPE tissue of CD274 positive cases, by normalizing absolute values to $\beta$-actin. Total RNA was extracted using Hybrid-R RNA purification kit (GeneAll Biotechnology Co. Ltd.) according to the manufacturer protocol. RNA samples were quantified using the highly sensitive Qubit quantitation assays (Thermo Fisher Scientific). Equal amounts of RNA were reverse transcribed using a HyperScript ${ }^{\mathrm{TM}}$ Reverse Transcriptase (GeneAll Biotechnology Co. Ltd.) with oligod $(\mathrm{T})$ primers according to the manufacturer's instruction (Table I) PCR was performed with Fast-Plus EvaGreen gene expression master mix, cDNA, nuclease free water, forward and reverse primers in a $20 \mu \mathrm{l}$ final reaction volume. The amplification cycles were performed by the Rotor Gene - Q System (Qiagen) as follows, hold at $95^{\circ} \mathrm{C}$ for $3 \mathrm{~min}$, followed by amplification for 40 cycles, each cycle consisting of denaturation at $95^{\circ} \mathrm{C}$ for $5 \mathrm{~s}$, annealing at $55^{\circ} \mathrm{C}$ for $30 \mathrm{~s}$. The housekeeping gene $\beta$-actin (Table I) expression level was used as an internal control to evaluate the integrity of each sample. Relative expression level of mRNA of PDL1 was calculated and scored using

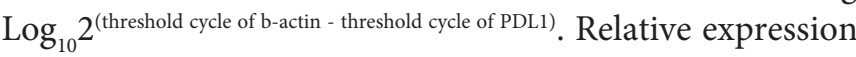
was scored on a $\log 10$ scale $(0-2)$.

\section{RESULTS}

Neoplastic cells showed PD-L1 expression in 34 of 222 (15.3\%) sarcomas (Table II). 5/13 (39\%) undifferentiated pleomorphic sarcomas, 6/18 (33\%) malignant peripheral nerve sheath tumors, 5/16 (31\%) dedifferentiated liposarcomas, 4/19 (21\%) rabdomyosarcomas, 2/16 (13\%)
Table I: The forward and reverse primers used in the real-time polymerase chain reaction analyses for $\mathrm{CD} 274$ and $\beta$-Actin genes.

\begin{tabular}{ll}
\hline Genes & \multicolumn{1}{c}{ Primers } \\
\hline$\beta$-actin (forward) & AGAGCTACGAGCTGCCTGAC \\
\hline$\beta$-actin (reverse) & AGCACTGTGTTGGCGTACAG \\
\hline CD274 (forward) & AGGGCATTCCAGAAAGATGAG \\
\hline CD274 (reverse) & TGTTCTTATCCTCCATTTCCCA \\
\hline
\end{tabular}

Table II: PD-L1 expression among various sarcomas

\begin{tabular}{lc}
\hline Type of Sarcoma & $\begin{array}{c}\text { PD-L1 } \\
\text { Positivity }\end{array}$ \\
\hline Undifferentiated Pleomorphic Sarcoma & $5 / 13(39 \%)$ \\
\hline Malignant Peripheral Nerve Sheath Tumor & $6 / 18(39 \%)$ \\
\hline Dedifferentiated Liposarcoma & $5 / 6(31 \%)$ \\
\hline Rhabdomyosarcoma & $4 / 19(21 \%)$ \\
\hline Epithelioid Sarcoma & $2 / 16(13 \%)$ \\
\hline Leiomyosarcoma & $2 / 15(13 \%)$ \\
\hline Synovial Sarcoma & $3 / 26(12 \%)$ \\
\hline Myxoid Liposarcoma & $1 / 18(6 \%)$ \\
\hline Extraskeletal Myxoid Chondrosarcoma & $1 / 2(50 \%)$ \\
\hline Alveolar Soft Part Sarcoma & $1 / 3(33 \%)$ \\
\hline Parachordoma/Myoepithelioma & $1 / 3(33 \%)$ \\
\hline Pleomorphic Liposarcoma & $1 / 5(20 \%)$ \\
\hline Angiosarcoma & $1 / 7(14 \%)$ \\
\hline Ewing sarcoma & $1 / 8(13 \%)$ \\
\hline Solitary Fibrous Tumor/Hemangiopericytoma & $0 / 18$ \\
\hline Desmoplastic Round Cell Tumor & $0 / 14$ \\
\hline Ewing-like sarcoma & $0 / 6$ \\
\hline Epithelioid hemangioendothelioma & $0 / 5$ \\
\hline Clear Cell Sarcoma & $0 / 4$ \\
\hline Myxofibrosarcoma & $0 / 4$ \\
\hline Low Grade Fibromyxoid Sarcoma & $0 / 2$ \\
\hline
\end{tabular}

epithelioid sarcomas, 2/15 (13\%) leiomyosarcomas, 3/26 (12\%) synovial sarcomas, 1/18 (6\%) myxoid liposarcoma, $1 / 2$ (50\%) extraskeletal myxoid chondrosarcoma, $1 / 3$ (33\%) alveolar soft part sarcoma, 1/3 (33\%) parachordoma/ myoepithelioma, 1/5 (20\%) pleomorphic liposarcoma, 1/7 (14\%) angiosarcoma, and 1/8 (13\%) Ewing sarcoma showed PD-L1 expression (Figure 1). Solitary fibrous tumor/hemangiopericytomas $(\mathrm{n}=18)$, desmoplastic round cell tumors $(n=14)$, Ewing-like sarcomas $(n=6)$, epithelioid hemangioendotheliomas $(n=5)$, clear cell sarcomas $(n=4)$, myxofibrosarcomas $(n=4)$, and low-grade fibromyxoid sarcomas $(\mathrm{n}=2)$ were all negative. 


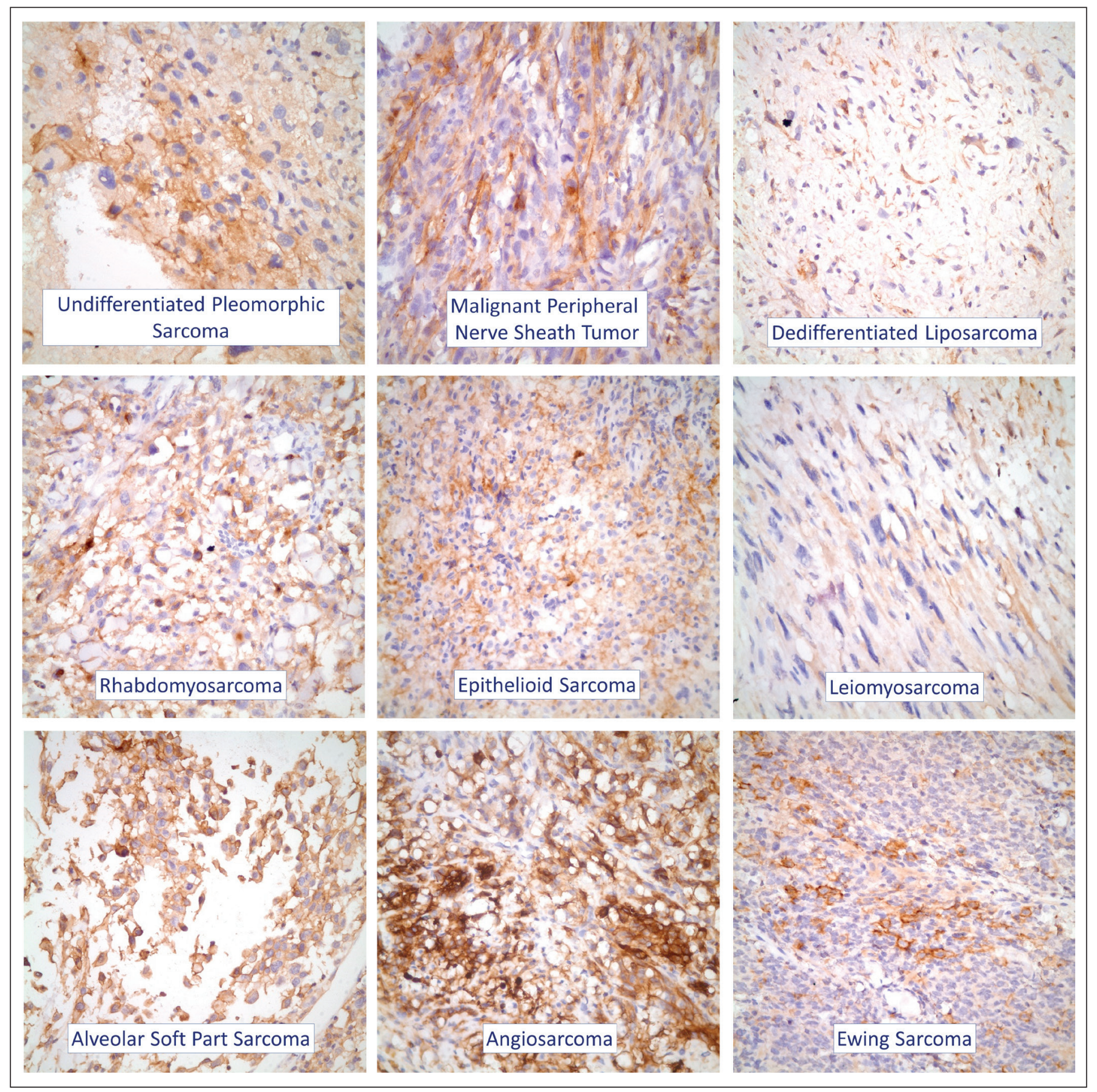

Figure 1: Examples of PD-L1 expression in various sarcomas.

PD-L1 expression in tumor infiltrating inflammatory cells was present in 32 of 222 (14.4\%) sarcomas (Figure 2A-C). Only 4 of 34 (11.8\%) PD-L1 positive sarcomas, 3 of which were dedifferentiated liposarcomas, also had PD-L1 positive inflammatory cells within the neoplasm (Table III).

Quantitative real-time PCR revealed that 16 of 34 (47\%) cases showed significant (>1 log) but low-level PD-L1
mRNA overexpression (Figure 3). None of the cases showed $>2 \log$ mRNA expression.

\section{DISCUSSION}

With this sarcoma series investigating PD-L1 expression with 222 cases, we have shown that a small subset $(\sim 15 \%)$ of sarcomas express PD-L1 in neoplastic cells. The highest PD-L1 expression among sarcomas was reported from the 
Republic of Korea: In one series of 105 sarcomas, PD-L1 was positive in $65 \%$ of the cases (8), and more recently, Kim et al. found that $43 \%$ of 82 sarcomas expressed PDL1 (9). This relatively high PD-L1 expression prevalence may be possibly due to the use of different antibodies (R\&D System antibody, clone 130021 [polyclonal] and Santa Cruz Biotechnology, clone H-130 [monoclonal]), cut-off levels (10\% cut-off and combined score above 8 ), staining methods or retrieval technique $(8,9)$. It is known that antibodies against PD-L1 are not identical and the use of some clones are not recommended (10). High levels of PD-L1 expression from Korea may also indicate the possible impact of race on differential expression of immunomodulatory mechanisms. Similar to our results, expression prevalence seems to be lower in the Western population. In a comprehensive immunohistochemical analysis of PD-L1 in 5536 cases, 59 of $986(6 \%)$ demonstrated PD-L1 expression over 5\% of tumor cells (11). D'Angelo et al. (12) and Matthew et al. (13) from USA reported that $12 \%$ of 50 sarcomas and $20 \%$ of 85 sarcomas were positive for PD-L1, respectively. Similarly, Paydas et al. from Turkey recorded a PD-L1 positivity of $29 \%$ of 65 cases (14). Although we used tissue microarrays unlike many of the previous studies, our result of $15.3 \%$ is comparable with previous results of D'Angelo et al., Matthew et al., and Paydas et al., that used DAKO antibody with $1 \%$ cutoff, Cell Signaling antibody with 5\% cut-off, and Acris Antibody with 5\% cut-off, respectively. We believe that a relatively lower figure of $6 \%$ by Inaguma et al. is mainly due to the absence of cases diagnosed as undifferentiated pleomorphic sarcomas and dedifferentiated liposarcomas in their series (11).

Malignant mesenchymal tumors showing predominantly pleomorphic morphology, such as undifferentiated pleomorphic sarcomas, malignant peripheral nerve sheath tumors, and dedifferentiated liposarcomas demonstrated more PD-L1 expression (over 30\% of the cases) than other types of sarcomas. In line with this, in a study including 53 MPNSTs, $13 \%$ were shown to express PD-L1 in tumor cells (15), while in others $25 \%$ and $21 \%$ of MPNSTs were PD-L1 positive $(11,14)$. Some studies also confirmed a significant correlation between PD-L1 expression and advanced clinicopathological parameters, such as higher clinical stage, presence of distant metastasis, as well as higher histological grade, poor differentiation of tumor, and tumor necrosis $(8,9)$. Moreover, both PD1and PD-L1 positivity were reported to be independent prognostic factors for overall survival by multivariate analysis; cases with a PD1+/PD-L1+ phenotype had the worst prognosis, which may benefit from PD1-based
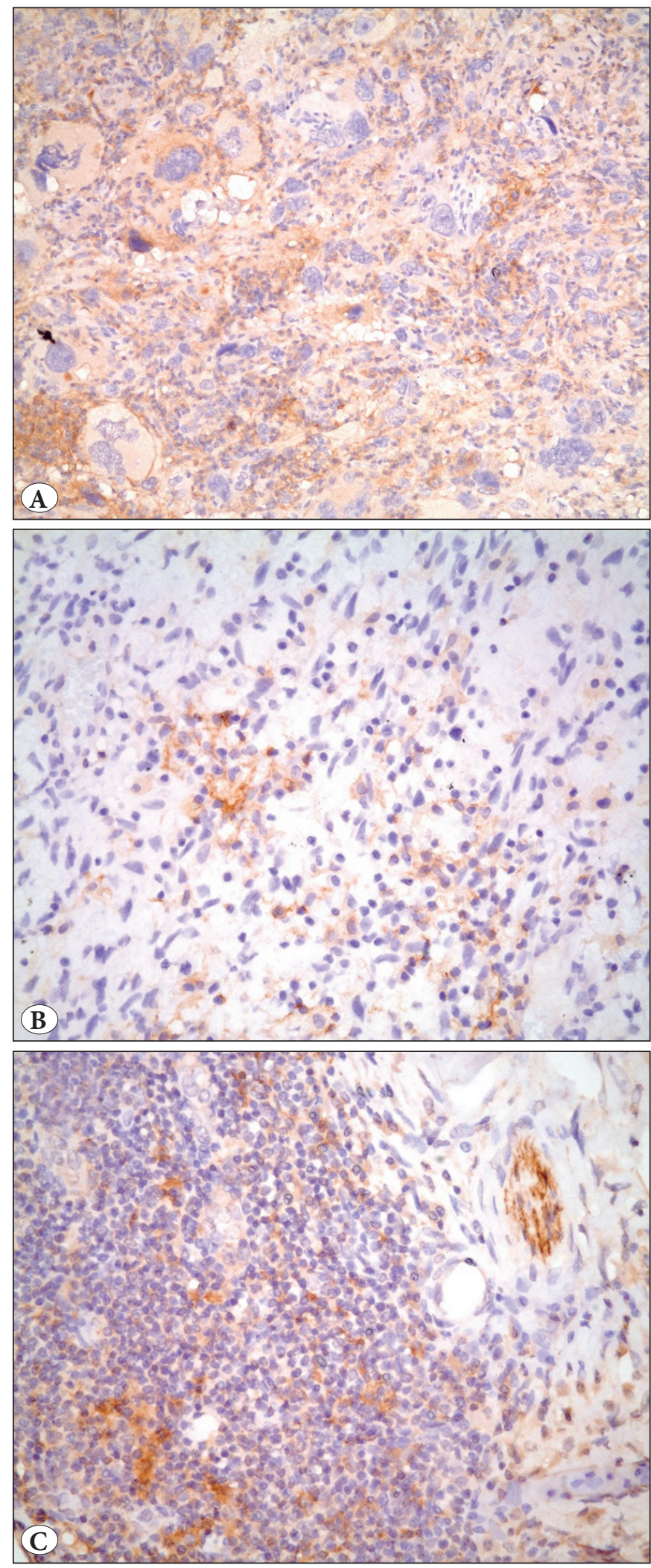

Figure 2: A) Both tumor cells and tumor infiltrating inflammatory cells were positive in a dedifferentiated liposarcoma (PD-L1; x200). B-C) In 13\% of cases, only inflammatory cells were positive (PD-L1;x400). 
immunotherapy $(8,9)$. Besides, few low-grade sarcomas, such as myxoid liposarcoma without a high-grade round cell component also showed PD-L1 expression. Knowing ththat chemotherapy and radiotherapy has very limited effect on low grade sarcomas, anti-PD-L1 treatment may be the best option to prevent progression in metastatic low grade sarcomas showing PD-L1 expression. Larger series are required to assess the prevalence of PD-L1 expression among extraskeletal myxoid chondrosarcomas, alveolar soft part sarcomas, and parachordoma/myoepitheliomas as PD-L1 was positive in a significant percent of the low number of cases. Unfortunately, various sarcoma types including solitary fibrous tumor/hemangiopericytoma, desmoplastic round cell tumor, Ewing-like sarcoma, epithelioid hemangioendothelioma, clear cell sarcoma, myxofibrosarcoma, and low-grade fibromyxoid sarcoma, many of which are high-grade by definition, did not express PD-L1, thus having less potential to benefit from anti-PD-L1 therapies.

Expression of PD-L1 in tumor-infiltrating lymphocytes and macrophages was previously documented in sarcomas in detail $(8,12)$. Inflammatory cells are present in almost all of the sarcomas, and 30\% of lymphocytes and $58 \%$ of macrophages expressed PD-L1 (12). Paydas et al. also recorded that $30 \%$ of cells forming tumor microenvironment expressed PD-L1 (14). Our result of $14.4 \%$ PD-L1 positive tumor-infiltrating inflammatory cells seems to be lower than expected, possibly due to the use of tissue microarrays instead of whole sections. We found a very low level (4\%) of co-expression of PD-L1 in both tumor and tumor infiltrating inflammatory cells. In the series of Paydas et al., 21\% of the sarcomas showed PDL1 expression in both the tumor microenvironment and tumor cells; and Kaposi sarcoma, not surprisingly, was the most common sarcoma with $80 \%$ of the cases showing this phenotype (14). This high level of co-expression could be attributed to the phenomenal role of the immune system on the development and regression of this tumor.

Previously, PD-L1 expression was also demonstrated in both mRNA and protein level in a subset of osteosarcomas (7). In their study, 9 samples had high-level expression (24\%) with over $3 \log$ fold increase, 19 samples (50\%) had

Table III: PD-L1 expression in tumor and accompanying inflammatory cells

\begin{tabular}{llccc}
\hline & \multicolumn{3}{c}{ Tumor Infiltrating Inflammatory Cells } \\
\cline { 2 - 4 } \multicolumn{2}{c}{ Neoplastic Cells } & PD-L1 + & PD-L1 - & $34(15.3 \%)$ \\
\hline & PD-L1 + & $4(1.8 \%)$ & $30(12.5 \%)$ & $188(84.7 \%)$ \\
\cline { 2 - 4 } & PD-L1 - & $28(12.6 \%)$ & $160(72.1 \%)$ & $222(100 \%)$ \\
\hline
\end{tabular}

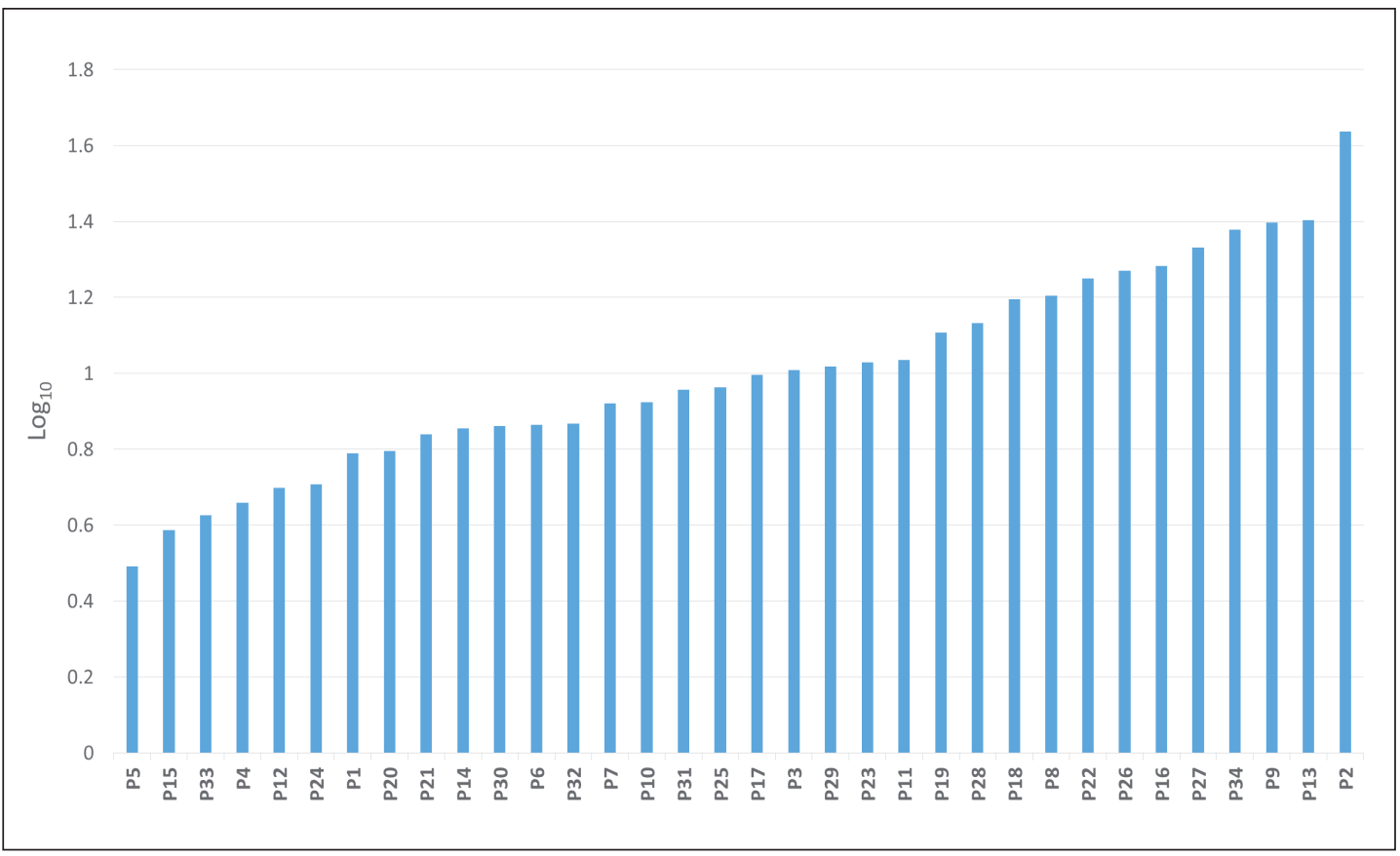

Figure 3: Quantitative PCR results of $\mathrm{PD}-\mathrm{L} 1$ positive cases. 
intermediate expression, 4 (10\%) had low-level expression, and $6(16 \%)$ were negative. More recently, only 5 of 89 (5.6\%) non-small cell lung carcinomas were shown to have a PD-L1 gene amplification, which is associated with worse prognosis (16). In our series, immunohistochemically PDL1 positive cases showed a low to intermediate level of PD-L1 mRNA expression by quantitative PCR. Our results indicate that overexpression of PD-L1 protein is mainly modulated by post-translational mechanisms rather than at the transcriptional level, and the mechanism of PD-L1 overexpression differs among different kind of tumors.

In conclusion, we have shown PD-L1 expression in a subset of sarcomas both on the protein and mRNA level. Highgrade sarcomas including undifferentiated pleomorphic sarcomas, dedifferentiated liposarcomas and MPNSTs tend to show more frequent PD-L1 expression. Quantitative PCR results indicate the influence of post-translational modifications rather than transcriptional level as the possible mechanisms of PD-L1 overexpression in sarcomas. The results of ongoing clinical trials are necessary to further assess the effect of anti PD-L1 drugs on sarcomas showing PD-L1 expression.

\section{ACKNOWLEDGEMENTS}

The authors thank to Elif Nihan Çetin for her technical support. This study was supported by the Hacettepe University Scientific Research Unit, Grant number: THD2015-5202.

\section{REFERENCES}

1. Chemnitz JM, Parry RV, Nichols KE, June CH, Riley JL. SHP1 and SHP-2 associate with immunoreceptor tyrosine-based switch motif of programmed death 1 upon primary human $\mathrm{T}$ cell stimulation, but only receptor ligation prevents $\mathrm{T}$ cell activation. J Immunol. 2004;173:945-54.

2. Velcheti V, Rimm DL, Schalper KA. Sarcomatoid lung carcinomas show high levels of programmed death ligand-1 (PDL1). J Thorac Oncol. 2013;8:803-5.

3. Velcheti V, Schalper KA, Carvajal DE, Anagnostou VK, Syrigos KN, Sznol M, Herbst RS, Gettinger SN, Chen L, Rimm DL. Programmed death ligand-1 expression in non-small cell lung cancer. Lab Invest. 2014;94:107-16.

4. Hamanishi J, Mandai M, Iwasaki M, Okazaki T, Tanaka Y, Yamaguchi K, Higuchi T, Yagi $\mathrm{H}$, Takakura K, Minato N, Honjo T, Fujii S. Programmed cell death 1 ligand 1 and tumorinfiltrating CD8+ T lymphocytes are prognostic factors of human ovarian cancer. Proc Natl Acad Sci U S A. 2007;104:3360-5.

5. Hamanishi J, Mandai M, Matsumura N, Abiko K, Baba T, Konishi I. PD-1/PD-L1 blockade in cancer treatment: Perspectives and issues. Int J Clin Oncol. 2016;21:462-73
6. Thompson RH, Gillett MD, Cheville JC, Lohse CM, Dong H, Webster WS, Krejci KG, Lobo JR, Sengupta S, Chen L, Zincke H, Blute ML, Strome SE, Leibovich BC, Kwon ED. Costimulatory B7-H1 in renal cell carcinoma patients: Indicator of tumor aggressiveness and potential therapeutic target. Proc Natl Acad Sci U S A. 2004;101:17174-9.

7. Shen JK, Cote GM, Choy E, Yang P, Harmon D, Schwab J, Nielsen GP, Chebib I, Ferrone S, Wang X, Wang Y, Mankin H, Hornicek FJ, Duan Z. Programmed cell death ligand 1 expression in osteosarcoma. Cancer Immunol Res. 2014;2:690-8.

8. Kim JR, Moon YJ, Kwon KS, Bae JS, Wagle S, Kim KM, Park HS, Lee H, Moon WS, Chung MJ, Kang MJ, Jang KY. Tumor infiltrating PD1-positive lymphocytes and the expression of PDL1 predict poor prognosis of soft tissue sarcomas. PLoS One. 2013;8:e82870.

9. Kim C, Kim EK, Jung H, Chon HJ, Han JW, Shin KH, Hu H, Kim KS, Choi YD, Kim S, Lee YH, Suh JS, Ahn JB, Chung HC, Noh SH, Rha SY, Kim SH, Kim HS. Prognostic implications of PDL1 expression in patients with soft tissue sarcoma. BMC Cancer. 2016;16:434.

10. McLaughlin J, Han G, Schalper KA, Carvajal-Hausdorf D, Pelekanou V, Rehman J, Velcheti V, Herbst R, LoRusso P, Rimm DL. Quantitative assessment of the heterogeneity of PD-L1 expression in non-small-cell lung cancer. JAMA Oncol. 2016;2:46-54.

11. Inaguma S, Wang Z, Lasota J, Sarlomo-Rikala M, McCue PA, Ikeda $\mathrm{H}$, Miettinen M. Comprehensive immunohistochemical study of programmed cell death ligand 1 (PD-L1): Analysis in 5536 cases revealed consistent expression in trophoblastic tumors. Am J Surg Pathol. 2016;40:1133-42.

12. D'Angelo SP, Shoushtari AN, Agaram NP, Kuk D, Qin LX, Carvajal RD, Dickson MA, Gounder M, Keohan ML, Schwartz GK, Tap WD. Prevalence of tumor-infiltrating lymphocytes and PD-L1 expression in the soft tissue sarcoma microenvironment. Hum Pathol. 2015;46:357-65.

13. Matthew S, Mackinnon AC. Programmed Death-Ligand 1 expression in sarcomas, a clinical a pathologic study [abstract]. Modern Pathology. 2016;29 (suppl 2):22A-23A.

14. Paydas S, Bagir EK, Deveci MA, Gonlusen G. Clinical and prognostic significance of $\mathrm{PD}-1$ and $\mathrm{PD}-\mathrm{L} 1$ expression in sarcomas. Med Oncol. 2016;33:93.

15. Shurell E, Singh AS, Crompton JG, Jensen S, Li Y, Dry S, Nelson S, Chmielowski B, Bernthal N, Federman N, Tumeh P, Eilber FC. Characterizing the immune microenvironment of malignant peripheral nerve sheath tumor by PD-L1 expression and presence of CD8+ tumor infiltrating lymphocytes. Oncotarget. 2016;7:64300-8

16. Ikeda S, Okamoto T, Okano S, Umemoto Y, Tagawa T, Morodomi Y, Kohno M, Shimamatsu S, Kitahara H, Suzuki Y, Fujishita T, Maehara Y. PD-L1 is upregulated by simultaneous amplification of the PD-L1 and JAK2 genes in non-small cell lung cancer. J Thorac Oncol. 2016;11:62-71. 